NBER WORKING PAPER SERIES

\title{
THE WORLD PRICE OF FOREIGN EXCHANGE RISK
}

\author{
Bernard Dumas \\ Bruno Solnik
}

Working Paper No. 4459

\author{
NATIONAL BUREAU OF ECONOMIC RESEARCH \\ 1050 Massachusetts Avenue \\ Cambridge, MA 02138 \\ September 1993
}

Both authors received financial support for this project from the "Fondation Nationale pour l'Enseignment de la Gestion des Entreprises" via the French Finance Association and from the HEC Foundation. Much of the work on this paper was done while Dumas was at the Wharton School of the University of Pennsylvania, where he received the support of the Nippon Life Professorship. Both authors are immensely grateful to Wayne Ferson, Campbell Harvey and William Perraudin who generously supplied sample GMM programs. Ferson and Harvey provided us with a bounty of comments and suggestions. Helpful comments have been received from Fischer Black, Geert Bekaert, Eunice Beth Mansour, John Campbell, John Cochrane, Michael Gibbons, Jim Hodder, Charles Jacklin, Andy Lo, Hayne Leland, Karen Lewis, Richard Marston, Antonio Mello, Mark Rubinstein, Robert Stambaugh, Richard Stehle, George Tauchen, Ingrid Werner and from participants at the CEPR workshop on International Finance (Bank of Spain, Madrid, October 1991), the Wharton lunch group, the NBER Asset Pricing program meeting (March 1992), the Stockholm School of Economics, Duke University, the H.E.C. School of Management, the Massachusetts Institute of Technology, Stanford University, the University of California at Berkeley, the French Finance Association international meeting (June 1992), the European Finance Association (September 1992), and the London School of Economics. The kind guidance of Sengkee Koh was most helpful. This paper is part of NBER's research programs in Asset Pricing and International Finance and Macroeconomics. Any opinions expressed are those of the authors and not those of the National Bureau of Economic Research. 


\title{
THE WORLD PRICE OF FOREIGN \\ EXCHANGE RISK
}

\begin{abstract}
We consider a world capital market in which the investor population is heterogenous. Investors of different countries differ in the prices of goods at which they consume the income from their investments. In such a setting, the international CAPM incorporates rewards for exchange rate risk, in addition to the traditional reward for market-covariance risk. The aim of the paper is to determine whether these additional risk premia empirically play a significant role in the pricing of securities. The test being conducted is a test of a conditional version of the CAPM. It builds on the recent empirical literature which points out that stock market returns may, to some extent, be predicted on the basis of a number of instrumental variables, such as interest rates and dividend yields. All previous tests of the international CAPM with exchangerisk premia have been tests of the unconditional version and have been inconclusive.
\end{abstract}

Bernard Dumas HEC School of Management 78351 Jouy-en-Josas Cedex France and NBER
Bruno Solnik HEC School of Management 78351 Jouy-en-Josas Cedex France 


\section{Introduction}

With the work of Harvey $(1989,1991)$, an opportunity has arisen to test the international asset pricing model in its conditional form, without having to pre-specify the behavior of second moments of rates of return.

In the CAPM of Solnik (1974), Sercu (1980), Stulz (1981) and Adler-Dumas (1983), exchange-rate risk is priced. The model contains risk premia which are based on the covariances of assets with exchange rates, In addition to the traditional premium based on the covarlance with the market portfolio. ${ }^{1}$ These new premia are present because of deviations from Purchasing-Power Parity. In consuming their capital income, Investors of different countries have access to goods at prices which are unequal. ${ }^{2}$ Therefore, they view differently the returns from the same assets. The Japanese grant a premium on assets which protect their real purchasing power; this is a different premium from the one granted by the U.S. investors. Hence, the two premia show up as separate terms in the aggregated model.

We call "international" a CAPM which contalns additional terms to reward exchange-rate risk while we call "classic" a CAPM which does not contain such terms and in which there is only one risk premium based on the covariance of the asset return with the market portfolio. ${ }^{3}$ The main goal of the present paper is to discriminate empirically between the two models and to test the null hypothesis that exchange-rate risk receives a zero price, against the international CAPM alternative.

Attempts have been made in the past at testing the international CAPM;

${ }^{1}$ See Equation (14) in Adler-Dumas (1983).

${ }^{2}$ The comparison is done after conversion into a common currency unit, of course.

${ }^{3}$ The classic CAPM is sometimes applied to international data (as in Harvey (1991)) using the world market portfolio as a basis for pricing. 
see Solnik (1974) and Stehle (1977). They were based on the unconditional version of the International CAPM. These attempts, which will be replicated below, have been inconclusive. Recently, Korajczyck and Vlallet (1989) have perforwed tests of several versions of the unconditional classlc CAPM. They tend to reject all of them.

It is natural to test the CAPM in its conditional form. It is bad enough that the econometrician does not know what investors know and, therefore, must deal with a somewhat integrated, partially faulty CAPM. One would not want to carry the defect further by ignoring the conditioning information which is obviously avallable to Investors, such as interest rates, equity prices etc.. These must appear in emplrical tests in the form of instrumental variables.

The next issue is how to test a conditional CAPM. Many methods have been proposed. Of necessity, they rely on extraneous assumptions concerning the behavior of the moments of the probability distribution of returns in relation to the instrumental variables, and/or on the behavior of the market prices of risk. The major distinction between methods is the assumption made regarding the behavior of second moments. In the latent varlable approach, 4 second moments are assumed constant and market prices of risk (the latent variables in question) are related inearly to the Instrumental varlables. ${ }^{5}$ Generallzed ARCH-M methods ${ }^{6}$ specify second moment behavior and assume that the market price of risk is constant. In Ferson and Harvey (1991a, b), as in Fama and

${ }^{4}$ See Hansen and Hodrick (1983), Hodrick and Srivastava (1984).

In the latent variable approach, conditional first moments need not be specified.

${ }^{6}$ For an application of the GARCH-M methodology to international data, see Engel and Rodrigues (1989), Hodrick (1987), Chan, Karolyi and Stulz (1992). Chan, Karolyi and Stulz conducted a conditional bivariate estimation of a GARCH-M model of two assets, a U.S. equity Index and a forelgn equity index. This was a conditional classic CAPM since no exchange-rate risk premium was modelled. They found some evidence of a risk premium based on the covariance risk with the international market portfolio. 
MacBeth (1973), the second moments are obtained by a separate, first-pass estimation and then the model is tested. This last method relles on an assumption concerning the speed at which second moments vary.

The alternative is to restrict the behavior of the market prices of risk, as was done in the latent-varlable approach. Recently, Harvey (1989) has proposed a method in which the prices of risk are assumed constant and then the second moments are free to move about in an unspecified way. Furthermore, for the special case in which the CAPM features only one risk premium, he has proposed a substitution which allows both the market price of $r i s k$ and the second moments to evolve in an unspecifled way. In Harvey (1991), the classic CAPM is applied to international data using that technique. Unfortunately, the technique is not generalizable to more than one risk premium and has the undesirable implication that the CAPM is forced to be exactly verifled when applied to the ex post return on the market portolio.?

In the present paper, we Intend to apply the approach of Harvey (1989). but restricting the market prices of risk to be linear functions of the instrumental varfables, in a manner similar to the latent-variable approach.

The major shortcoming of any CAPM model is that the model does not specify the choice of Instrumental variables. CAPMs are partial-equilibrium models reflecting the equilibrium in the financial market only. The link with underlying physical and monetary variables is left unspecified. Generalequilibrium models would make that link explicit and would in this respect be preferable. However, existing general-equilibrium models of the international economy are extremely simplistic. It would probably be premature to undertake any empirical tests at this stage. Furthermore, most of the underlying physical variables of the economy are observed with measurement errors and

7 The market's pricing error - - h in Harvey's notation, as defined by his Equation (5) with $j-m-$ is identEically equal to zero. 
with, at best, quarterly frequency whereas the financial variables which we wish to explain are observed with greater frequencles. Hence, even if the model under test did specify the cholce of underlying varlables, these would have to be proxied by endogenous variables that are observed frequently, such as financial market variables. The search for proxies would be guided by the model and would, therefore, introduce a degree of arbitrariness smaller than that introduced by the arbitrary specification of instrumental variables in a CAPM. The methodological gain would be undeniable but the end result may turn out to be very simflar. In Section 2, we discuss our cholce of instrumental variables.

For consistency, a CAPM which is conditional should also be multiperiodic (or dynamic). It is inconsistent to assume that investors base their estimates of future returns on current information, and then to assume that these same investors will not anticipate that the information, at the next investment point in time, w111 have shifted. If they do anticipate information shifts, Investors adjust their portfolio cholce today in an attempt to hedge those shifts, thereby introducing in the CAPM more premia, which are based on the covariances of asset returns with changes in the instrumental variables. Hence, the theory leads to an equilibrium relation which includes numerous risk premia linked to possible shifts in the information set. This is true equally in the classic and the international CAPMs. A test of a full-blown conditional, international and dynamic CAPM is beyond our computational capabilities at the present time. But, in the last section of this paper, we attempt to throw some light on the choice one faces. Which is more important? Taking into account exchange risk premia or dynamic hedging premia?

The paper is organized as follows. Section 1 lays out the model and the

${ }^{8}$ See Merton (1973). 
econometric method to be used. Section 2 describes the data and some summary statistics concerning them. In Section 3, we estimate the conditional version of the international CAPM by the Generalized Method of Moments and conclude that the model is not rejected by the data. Section 4 contains the main tests in which we compare the international and the classic, conditional CAPMs and test for the price of exchange risk. In Section 5, we examine the role of the conditioning, fnstrumental variables; in particular, we test the hypothesis of zero price of exchange risk in the unconditional, international CAPM. In Section 6, we perform some validation experiments, including out-of-sample experiments, and in Section 7 we test whether the world capital market - made up of the stock and the forelgn exchange markets - Is integrated. In section 8, we run a comparison between international and dynamic CAPMs.

\section{Model and econometric strategy}

\subsection{The classic and international CAPMs with Time-Varying Moments}

This study focuses on conditional, asset pricing restrictions of a static nature. There are $L+1$ countries, a set of $m=n+L+1$ assets $\cdots$ other than the measurement-currency deposit, - comprised of $n$ equities or portfollos of equities, L non-measurement-currency currency deposits and the world portfolio of equities which is the mth and last asset. The non-measurement-currency deposits are singled out by observing the above order in the list; i.e., they are the $(n+1)$ st to $(n+L)$ th assets.

The international Capital Asset Pricing model is Equation (14) In Adler and Dumas (1983):

$$
E\left[r_{j t} \mid \Omega_{t-1}\right]-\sum_{i-1}^{L} \lambda_{i, t-1} \operatorname{Cov}\left[r_{j t}, r_{n+1, t} \mid \Omega_{t-1}\right]+\lambda_{m, t-1} \operatorname{Cov}\left[r_{j t}, r_{m t} \mid \Omega_{t-1}\right]
$$


where $r_{j t}$ is the nominal return on asset or portfollo $j, j-1 \ldots$, from time $t$ - 1 to $t$, in excess of the rate of interest of the currency in which returns are measured, $r_{m t}$ is the excess return on the world market portfolio and $\Omega_{t-1}$ is the information set which investors use in choosing their portfolios. The time-varying coefficlents $\lambda_{i, t-1}, 1-1 \ldots L$, are the world prices of exchange rate risk. The time-varying coefficlent $\lambda_{m, t-1}$ is the world price of market risk.

The model takes into account the fact that investors of different countries view returns differently; Equation (1.1) is the result of an aggregation over the several categories of investors. The covariances with exchange rates are present because of the optimal exchange-risk hedging behavior of the various investors. In truth, these should be covariances of rates of return on assets with changes in PPP (Purchasing-Power Parity) deviations between countries. However, in this study we consider a world restricted to countries in which local currency inflation risk (to a one-month horizon) has been negligible. We, therefore, identify PPP deviations changes with exchange rate changes. 9

By contrast, the classic CAPM ignores investor diversity and assumes, in effect, that everyone in the world translates returns into consumption as do the residents of the reference currency country. Hence, no exchange-risk hedging premium appears. In the above notations, the restriction of the international CAPM to the classic CAPM is stated as:

$$
\lambda_{i, t-1}=0 \quad i=1 \ldots L, \forall t
$$

${ }^{9}$ Although each investor looks at returns from his own currency's point of view, it is immaterial in which currency units the model is written. This is because the theoretical model assumes the absence of money 11lusion ( 1 .e., homogeneity of degree zero of the investors' utility functions in nominal wealth and local prices). 
We now rewrite the International CAPM in the most parsimonious way that we can find. We introduce a new notation, $M_{t}$, referring to the marginal rate of substitution between nominal returns at date $t$ and at date $t-1$ that is implied by the international CAPM. It is well known that the first-order condition of any portfolio choice problem may be written:

$$
E\left[M_{t} r_{t} \mid \Omega_{t-1}\right]=0
$$

or, equivalently:

$$
E\left[r_{j t} \mid \Omega_{t-1}\right]-\operatorname{Cov}\left(r_{j t},-M_{t} / E\left[M_{t} \mid \Omega_{t-1}\right] \mid \Omega_{t-1}\right) . \quad j-1, \ldots m
$$

Define $u_{t}$ as the relative unanticipated component of the marginal rate of substitution:

$$
u_{t}=1-M_{t} / E\left[M_{t} \mid \Omega_{t-1}\right]
$$

with the obvious property that:

$$
E\left[u_{t} \mid \Omega_{t-1}\right]=0
$$

One may then rewrite $(1.4)$ as:

$$
E\left[r_{j t} \mid \Omega_{t-1}\right]-E\left[r_{j t} u_{t} \mid \Omega_{t-1}\right], j=1, \ldots m .
$$

Define $h_{j t}$ as:

$$
h_{j t}=r_{j t}-r_{j t} u^{\prime} \quad j-1, \ldots \ldots m .
$$


$h_{j t}$ is a disturbance that is unrelated to the information $n_{t-1}$ under the null hypothesis that (1.7) holds. Indeed, (1.7) may be rewritten:

$$
E\left[h_{j t} \mid \Omega_{t-1}\right]-0, \quad j-1, \ldots m .
$$

The international CAPM gives a special form to the marginal rate of substitution and to its unanticipated component. Let $u_{t}$ be defined as:

$$
u_{t}=\lambda_{0, t-1}+\sum_{i-1}^{L} \lambda_{1, t-1} r_{n+1, t}+\lambda_{m, t-1} r_{m t} .
$$

Then, under (1.6), Equations (1.1) and (1.9) are equivalent. In (1.10), $\lambda_{0}, t$ 1 is whatever term is needed to bring about (1.6). The economic interpretation of Equation (1.10) is discussed below.

\subsection{Econometric specification}

In this subsection, we outline the empirical procedure that we are going to follow. We state two auxiliary assumptions that are needed. These will be discussed in subsection 1.3 .

Assumption 1 of the empirical analysis: the information $n_{t-1}$ is generated by a vector of instrumental variables $z_{t-1}$.

$z_{t-1}$ is a row vector of $\ell$ predetermined instrumental variables which reflect everything that is known to the investor. We discuss in Section 2 below our cholce of the $Z$ variables; some of them will be variables endogenous to the financial market. The $2 s$ in their 1 imited number will not constitute a full description of the state of the real-world economy. Assumption 1 is a strong 
assumption which does not simply limit the information set of the econometrician; it limits the Information set of the Investors and, therefore, their strategy space. ${ }^{10}$ Testing the CAPM under information set $n_{t-1}$ or under the information set generated by $z_{t-1}$ is not testing two different implications of the same theory of investment. The two tests refer to two different theories of investor behavior.

Next, we specify the way in which the market prices, $\lambda$, move over time. In a general equilibrlum setting these would probably be nonlinear functions of the exogenous varlables describing the state of the economy. Nonetheless, we now assume that the variables, $Z$, can serve as proxies for the state variables and that there exists an exact inear relationship between the $\lambda s$ and the $\mathrm{zs}: 11$

As sumption 2:

$$
\begin{aligned}
& \lambda_{0, t-1}=-z_{t-1} \delta, \\
& \lambda_{i, t-1}=z_{t-1} \phi_{i}, \quad \quad 1-1, \ldots L \\
& \lambda_{\text {m, t-1 }}=z_{t-1} \phi_{\text {m }} .
\end{aligned}
$$

Here the $\delta s$ and $\phi s$ are time-invarlant vectors of weights. Later on, we interpret Assumption 2 in relation to the literature. But we first get on with the specification of the econometric model.

Given Assumption 2 and the definition (1.10) of $u_{t}$, we have:

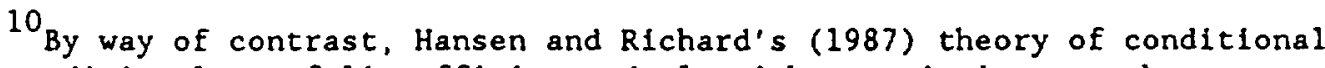
vs unconditional portfolio efficiency deals with restrictions on the econometrician's (or the outside observer's) information set, keeping the investor's (or the fund manager's) information set the same.

${ }^{11}$ This specification has some similarities with the latent-variable approach of Hansen and Hodrick (1983) and Gibbons and Ferson (1985). The $\lambda s$ are the "latent varlables". 


$$
u_{t}-\cdot z_{t-1} \delta+\sum_{t=1}^{L} z_{t-1} \phi_{1} r_{n+1, t}+z_{t-1} \phi_{m} r_{m t} \text {, }
$$

with $u_{t}$ satisfying (1.6). Equation (1.12) serves to define $u_{t}$ from now on.

We form the $1+m$ vector of residuals: $\epsilon_{t}=\left(u_{t}, h_{t}\right)$. Combining (1.6) and (1.9) under Assumption 1 yields: $E\left[c_{t} \mid z_{t-1}\right]-0$, which implies (but is by no means equivalent to) the unconditional condition:

$$
E\left[\epsilon_{t}^{2} t-1\right]-0 \text {. }
$$

The sample version of this last restriction is the moment condition:

$$
Z^{\prime} \in=0
$$

where $Z$ is a $T x l$ matrix and $\varepsilon$ a $T x(1+m)$ matrix, $T$ being the number of observations over time. This a total of $\ell \times(1+m)$ moment conditions.

In order to run a test of the above specification, we choose a number $m$ of assets which is large enough that the model imposes some overidentifying restrictions. We have $l$ parameters $\delta$ and $\ell x(L+L)$ parameters $\phi$; we choose $L+$ $1<m$ (more assets than countries) so that it is not possible to satisfy all the moment conditions exactly. We use Hansen's (1982) generalized method of moments (GMM) to minimize the average deviation from these moment conditions and thereby get the best estimates of the parameters $\delta$ and $\phi$. The deviations in the various moment conditions are weighted by a weighting matrix, w, which is the inverse of a consistent estimate of the covariance matrix of sample moment conditions. Under the null hypothesis that (1.6) and (1.9) hold, the value of the resulting quadratic form is asymptotically distributed $x^{2}$ with degrees of freedom equal to the number of orthogonality conditions minus the number of parameters. This being an asymptotic test, the number of observations plays no role in the determination of the degrees of freedom. Neither do distributional assumptions, provided that the conditions of the Central Limit Theorem are satisfled. 
As has been shown by Newey and West $(1987 a),{ }^{12}$ a similar statistic may be used to test the null hypothesis that some specific, additional restriction, or set of restrictions, binds the parameters. One computes the $x^{2}$ statistic in the absence of restriction and then again under the added constraints imposed on the model, but this time using the welghting matrix $w$ of the unconstrained model. The difference in the two $x^{2}$ statistics so obtained is itself $x^{2}$ distributed with as many degrees of freedom as there are new restrictions.

1.3 Discussion of the assumptions

Before we carry out our program of research, we now go back and Interpret Assumption 2 (Equations (1.11)).

We are aided in the interpretation of the assumptions by the marginal rate of substitution $M_{t}$ ' which, in the language of Hansen and Jagannathan (1991), is the "pricing kernel" Implied by the mean-variance theory of international asset pricing.

In Iine with Hansen and Jagannathan (1991), Equation (1.10) expresses the pricing kernel as a linear projection on a subspace of asset returns, namely the riskless return, the returns on the market portfolio and the returns on currencies. ${ }^{13}$ The projection has time-varying coefficients $\lambda$. Assumption 2 (Equation (1.11)) specifies how those coefficients vary over time as a function of the instrumental (or state) variables.

Our specification differs somewhat from most implementations of the Hansen-Jagannathan projection. Equation (1.10) does not project the pricing kernel, $M_{t}$, itself. It projects the unanticipated part, $u_{t}$, of the kernel or,

${ }^{12}$ See also Gallant and Jorgenson (1979), Eichenbaum, Hansen and Singleton (1988), Eichenbaum and Hansen (1990).

13 Nonlinear pricing kernels are applied to international returns by Bansal, Hsieh and Viswanathan (1992). 
equivalently, the kernel scaled down by its conditional expected value, which is left unspecified. Theoretically, that condftional expected value is equal to one over one plus the dollar rate of interest. By scaling the pricing kernel, we in effect cancel the requirement that the model should explain the level of the dollar rate at each point in time. We allow model estimation and testing to focus exclusively on the explanation of rates of return relative to the dollar rate.

Correspondingly, Assumption 2 concerns the coefficients of the projection of the scaled kernel. If these coefficients are linear functions of the instrumental variables, the coefficients of the projection of the straight kernel, $M_{t}$, would not generally be linear functions. In fact, in our formulation these latter coefficients are left incompletely specified on purpose. 14

\section{Data and preliminary statistics}

We consider the monthly excess return on equity and currency holdings measured in a common currency, the U.S. dollar. The excess return on an equity market is the return on that market (cum dividend) translated into dollars, winus the dollar one-month nominally risk-free rate. The return on a currency holding is the one-month interest rate ${ }^{15}$ of that currency compounded by the exchange rate variation relative to the U.S. dollar, minus the dollar onemonth risk-free rate.

In this study, we take four countries into account: Germany, the United

${ }^{14}$ Adding the theoretical requirement concerning the level of the dollar rate would allow us to say that the straight projection coefficients are linear functions of the instrumental variables divided by one plus the dollar rate. Since the dollar rate will be included among the instrumental variables, the straight coefficients would then be nonlinear functions of the instrumental variables.

${ }^{15}$ These are Euro-currency interest rates provided by Lombard Odier. 
Kingdom, Japan and the United States. More precisely, we consider eight assets in addition to the U.S. dollar deposlt: the equity index of each country, 16 a Deutschemark deposit, a Pound Sterling deposit, a Yen deposit and the world index of equities. In the CAPM, we include only three exchange risk premia as many as we have exchange rates in this world. There are missing risk premia in the CAPM since French investors in reality also play a role in the determination of the prices of German equities. These missing terms in the CAPM do not affect the consistency of our estimation since the moment conditions are that the hs are uncorrelated with the instrumental variables and not with the terms of the equation, as would be the case in ols. The limited number of terms considered in the CAPM does not invalidate our test of the CAPM condition (1.14).

The number of instrumental variables is 1 imited by the econometric methodology. Their choice is a sensitive question both from a conceptual and from an empirical point of view. Conceptually, the CAPM theory fails to specify the list of instrumental variables; if it did, not one of them could be omitted in a proper test of the conditional CAPM. Empirically speaking, we verify in Section 5 below that the choice of instrumental variables does make a difference to the results.

Our specification borrows from the work of others, done in unrelated contexts and on different data. ${ }^{17}$ The dividend yield, the average bond yield and the short-term interest rate provide some prediction of equity returns. ${ }^{18}$

\footnotetext{
${ }^{16}$ These are Morgan Stanley country indexes and the Morgan Stanley world index. See Harvey (1991) for an appraisal of these Indexes.

17 Hence, we are somewhat guilty of "data snooping" but not of "data mining"

${ }^{18}$ See Fama and French (1988), Breen, Glosten and Jagannathan (1989), Ferson and Harvey (1991), Harvey (1991) or Solnik (1993), among others. Other variables, such as the default spread, have been shown to have some predictive power.
} 
We also know that equity returns in January seem larger than during other months. Harvey (1991) has shown that U.S. Instruments have some power in predicting equity returns in foreign markets. The short-term interest-rate differential (equivalent to the forward premium) has been shown to help predict time variation in currency return. 19

Our list includes six instrumental variables: a constant, the excess rate of return on the world index lagged one month, a January dummy, ${ }^{20}$ the U.S. bond yield, ${ }^{21}$ the dividend yield on the U.S. Index and the one-month rate of Interest on a Eurodollar deposit. This cholce of instruments allows for a direct comparison with published tests of the classic CAPM applied to International data (e.g.. Harvey (1991)).

There is a legitimate concern that some of these instrumental varlables may not be stationary, thereby violating the assumptions of the Generalized Method of Moments. This may be the case for the dividend yield, the bond yield and the short-term rate of interest. To alleviate this problem, we do two things. First, in the empirical implementation the dividend yield and the bond yield are replaced by their difference with the short-term rate. Second, in Section 6 below we compare the results obtained with the level of the shortterm rate used as an instrument to the results obtained after first differencing the rate of interest. We verify that the results are not changed.

The prediction of non U.S. returns would have been aided by the inclusion of non U.S. interest rates in the set of instrumental variables. But we have not included them. Including all the rates would have expanded the set beyond

${ }^{19}$ See Cumby and Obstfeld (1984), Kaminsky and Peruga (1990), Giovannini and Jorion (1989), Bekaert and Hodrick (1992) and others.

20 In Japan, the fiscal year ends in March. There may be a case for introducing an April dummy variable.

${ }^{21}$ The index of bond yields is constructed by Lombard Odier; for a description, see Solnik (1993). 
our computational capabllities. Including for each asset return the own rate of interest only would have rendered heterogenous the set of Instruments, thereby raising thorny conceptual issues concerning the cholce of orthogonality conditions.

TABLE 1 GOES HERE

Table 1 contains some preliminary statistics on the rates of return am: the instrumental variables. Avallable Index level data cover the period January 1970 to December 1991 which is a 264 data point series. However, we work with rates of return and we need to lag the rate of return on the world index by one month in the instrumental-variable set; that leaves 262 observations spanning March 1970 to December 1991. Among instrumental variables, the U.S. bond yield, the U.S. dividend yield (both of them measured in excess of the Eurodollar rate) and the Eurodollar rate are fairly strongly correlated and all three are somewhat correlated with the lagged world equity return. In Table 1, as in all tables of this paper, excess rates of return on assets are coded as 0.01 for a $1 \%$ rate of return per month. The instrumental variables that are yields or rates of return (except for the lagged world index rate of return) are coded as 1 for $1 \%$ per year. Similar conventions on units have been used in the earlier literature.

Table 1 also contains OLS regressions of the various assets' returns on the instruments, in order to gauge the instruments' predictive ability. $R^{2} s$ are small but a number of coefficients are significant. In all equations the coefficient of the eurodollar rate is significant and negative. Admittedly, we are dealing with excess returns, which increases the size of that coefficient by one. Even without that, these would remain significant. The U.S. dividend yield plays a significant role in predicting U.S. stock returns. 
The January dummy and the U.S. bond yleld play a significant role in predicting Deutschemark returns. The January dummy plays a simllar role in the case of the Japanese Yen. Whereas other researchers have amply documented day-of-the-week effects in forelgn exchange rates, we are not aware of independent findings of month-of-the-year effects in currencles.

In comparing the $R^{2} s$ of the regressions of the various assets on the common U.S. instrument set, we may appraise the extent to which it is legitimate to use these U.S. Instruments rather than own-country instruments. The point to notice in Table 1 is that the $R^{2} s$ of the regressions for non U.S. assets exhibit no tendency of being lower than the $R^{2}$ of U.S. equity. Foster and Smith (1992) have pointed out that the set of Instruments of one country may appear to help predict another country's rate of return even though it is the wrong set of predictive variables, simply as a result of the correlation between the two countries' asset rates of returns. However, in calibrated simulations they indicate that, if such were the case, the spurious $R^{2}$ would be about 50 to 607 lower than that of the own-country prediction regression. 22 We see no such pattern in Table 1.

\section{Estimating the conditional. International CAPM with GMY}

TABLE 2 GOES HERE

The first order of business is to determine whether the international CAPM, which we have formulated, is viable. Table 2 contains the result of estimating the conditional, International CAPM on the data and the instrumental variables which we have described. The table displays the

\footnotetext{
${ }^{22}$ See their Table 5.
} 
estimates of the delta and the phi coefficients, which represent the way the market prices of risk vary over time. Several have strong $t$ statistics. ${ }^{23}$ The $x^{2}$ test of the overidentifying restrictions created by the CAPM has a P-value equal to 0.2276 . Hence:

Statement \#l: The conditional version of the International, static CAPM Is not rejected by the data.

In Sections 4 and 7 below, we test several hypotheses in the context of this model and we compare it to other models.

4. Estimating the conditional, classic CAPM and testing the hypothesis that exchange rate risk recelves a zero price in the conditional. International CAPM

In this section, we reach the main results of this paper concerning the relative desirability of the classic vs. International, conditional CAPMs and we show the significance of exchange risk pricing.

TABLE 3 GOES HERE

First, we estimate the conditional, classic CAPM, 1.e. not including the risk premia on exchange-rate covariance risk. The result is displayed in Table 3. The P-value is: 0.0052 . Hence:

${ }^{23}$ In reading the tables, recall that excess rates of return on assets are coded as 0.01 for a 17 rate of return per month. The instrumental variables that are yields or rates of return (except for the lagged world market rate of return) are coded as 1 for $1 \%$ per year. 
Statement \#2: The conditional version of the classic, static CAPM applied to International data is rejected.

This estimation is close to Harvey's (1991) but for the addition of currencles in the list of assets. 24

In this article, we are interested in determining whether exchange risk is priced. Considering how sharp the rejection is and in view of the earlier acceptance of the international CAPM, we should have no doubt that exchange risk is priced in the international financlal market. Nevertheless, a proper test is needed.

TABLE 4 GOES HERE

Since the classic and the international CAPMs are nested, we can treat the classic as the null hypothesis and the international as alternative hypothesis, in testing for the significance of exchange rate pricing. The null Is that every element of the $\phi_{1}$ vectors is zero (see restriction (1.2) and Assumption 2, Equation (1.11)). Following the Newey-West (1987a) prescription, we estimate the classic, conditional CAPM, holding the weighting matrix at its value estimated under the international, conditional CAPM. Table 4 shows the result. The $x^{2}$ constrained by the null is: 83.8436 which is much higher than the unrestricted $x^{2}$ which had been found for the international CAPM (28,8039); the $P$-value of the null hypothesis is: $10^{-5}$.

${ }^{24}$ Harvey (1991) used the default spread on bonds as an additional instrumental variables and did not include the dollar short interest rate as a separate instrument. He had a forecasting equation for each asset return, not just for the Marginal Rate of Substitution, as we do here (Assumption 2, Equation 1.12) with parsimony in mind. 
Statement \#3: The hypothesis of zero price on exchange rate risk $1 \phi_{1}=0$; $1=1 \ldots L$ ] in the conditional version of the International CAPY is rejected.

It is useful to determine which asset(s) of our list cause the classic CAPM to be rejected, while the international one is not. We seek an answer to this question by decomposing the $x^{2}$ statistic into components, each one of which represents the contribution of one asset. A perfect decomposition of this statistic is not possible because the covariances in the moment conditions applied to two different assets are not generally equal to zero. A partial response to the question is obtained by approximating the covariance matrix of moment conditions by the elements that belong to its diagonal blocks, each block corresponding to one asset. 25

TABLE 5 GOES HERE

Table 5 shows the decompositions of various $x^{2}$ based on neglecting the elements outside the dlagonal blocks. The last two lines of each column serve as a check that the $x^{2}$ so reconstructed is very close to the statistic measured originally. The first column of Table 5 contains the decomposition of the $\chi^{2}$ statistic which served to test the overidentifying restrictions of the classic CAPM (supporting Statement \#2); the second column contains the decomposition of the $x^{2}$ of the international CAPM (Statement \#1) and the third column pertains to the $x^{2}$ difference of the test of significance of exchange

25 It would be possible more formally to rerun the estimation, removing one asset each time and then testing whether the set of moment conditions corresponding to each asset holds, as suggested by Newey and West (1987a), Eichenbaum, Hansen and Singleton (1988, appendix C) and Gallant (1987). The procedure we use here is a summary procedure and is based on the same concept as the formal test. After identifying the asset which causes rejection, we do run a formal test (see below). 
risk premia (Statement \#3). It is apparent that the rejection of the classic CAPM as well as the rejection of the classic CAPM null are due primarly to the Deutschemark deposit, and secondarlly to the Japanese Yen deposit.

As a confirmation of this role of the Deustchemark, we also run a formal test in the manner of Newey and West (1987a), Elchenbaum, Hansen and Singleton (1988, appendix $C$ ) and Gallant (1987). To do that, we remove the Deutschemark from the list of assets and reestimate the parameters holding the weighing matrix at its value estimated under the full set of assets, removing from the Inverse welght matrix the rows and columns corresponding to the Deutschemark moment conditions. The drop in the objective function value is $x^{2}$ distributed with as many degrees of freedom as there are instrumental variables. The reduced $x^{2}$ is found to be equal to: 48.372 , while the $x^{2}$ under the full 1 ist of assets for the classic CAPM was 69.119 (Table 3). The p-value of the null hypothesis that the Deutschemark fits the classic CAPM is equal to 0.002 .

Table 5 also shows that the international CAPM, while not being rejected overall, seems to explain the German and British markets somewhat less well than does the classic CAPM. The two models have similar performances for other securities. The international CAPM predicts the marginal rate of substitution somewhat less well than does the classic CAPM.

Much interest in recent years has been focused on the question of knowing what moves risk premia in financial markets. Is the movement in risk premia mostly the result of the time-varying nature of risk or of the time-varying nature of the market reward per unit of risk? The latent varlable approach, for instance, was based on the premise that the risk coefficients (the betas) are constants while the market reward does all the work. The work of Ferson and Harvey (1991a, 1991b) is specifically geared at separating the effects of the two variations. In the present model, we have allowed both quantities to vary; the risk varies in a fashion which is unspecified; the rewards to risk 
$\left(\lambda_{1} s, \lambda_{m}\right)$ vary according to Assumption 2 . We are therefore in a position to throw some light on this debate. 26

We test the hypotheses that $\lambda_{m}$, and then the $\lambda_{1} s$, are time-invariant. The results are displayed in Table 4. The P-value of the nulls of time invariance are of the order of $10^{-6}$ and $10^{-7}$ :

Statement 1 4: The hypothesis that the price of market risk is timeInvariant in the conditional version of the international CAPM is rejected. The hypothesis that the market prices of forelgn exchange risks are timeinvariant is also rejected.

The significance of forelgn exchange risk premia in the international CAPM could be an artifact linked to the large outstanding amount of government bonds which have nominal denominations in various currencies. 27 These bonds are in investors' portfolios and should, perhaps, have been included in the market portfolio but have not been. ${ }^{28}$ It is at least conceivable that the foreign-exchange risk premia, that we measured empirically, are just proxies for the missing bond returns. We now test this possibility. For lack of a reliable theory indicating what share government bonds should receive in the market portfolio, we make the auxiliary assumption that the shares of those bonds in the market portfolio are constant. This joint hypothesis implies that there exist constants $\gamma_{i}$ such that:

${ }^{26}$ But we cannot quantify the relative importance of the two types of variations since we have left the second moments unspecifled.

27

We are grateful to Ingrid Werner for this observation.

${ }^{28}$ Under the principle of Ricardian equivalence they should not be, because government bonds, considered as an asset in investors' portfollos, are offset by future taxes that investors will have to pay to allow the government to pay off the bonds. But it is not clear to what extent this principle holds in practise. 


$$
\lambda_{i, t-1}-\gamma_{i} \lambda_{m, t-1} \quad \text { for all } t
$$

or, equivalently:

$$
\phi_{\mathbf{i}}-\boldsymbol{\gamma}_{\mathbf{i}} \phi_{\mathbf{m}}
$$

$\gamma_{1}$ is the share of bond $i$ in the market portfolio divided by one minus the share of all bonds ( $1 . e .$, the share of equities). The overidentifying restrictions of the international CAPM, with restriction (4.2) added, were tested and rejected with a $x^{2}-65.2233$ and 39 degrees of freedom leading to a p-value equal to 0.053 . The null hypothesis (4.2) was tested against the unrestricted international CAPM. The results are shown in Table 4. The p-value is of the order of $10^{-5}$.

Statement \#5: The forelgn-exchange risk premla that we have identified cannot be interpreted as proxies for missing bonds in the market portfollo.

While we have been able to conclude that exchange risk premia are statistically significant, the technique used here does not allow an estimation of the relative sizes of the various risk premia. It is indeed possible to compare the sizes of the various market prices of risk. A glance at Table 2 shows that the coefficients of the $\lambda_{i} s$ (market prices of exchange risk) are of the same order of magnitude as those of $\lambda_{m}$. However, risk premia are equal to market prices of risk times the ex ante measures of risk (covariances with exchange rates and with the market portfolio). Unfortunately, ex ante measures of risk are not avallable in our estimation. As has been mentioned, the econometric method used here (see section 1) has 
the property that it does not require the specification of the behavior of second moments. The flip side of that coin is that we cannot indicate the size of risk premia.

\section{The role of conditioning information}

TABLES 6 AND 7 GO HERE

One extreme way of measuring the impact of conditioning information is to do away with it and to estimate the unconditional forms of the two contending CAPMs. We do this by setting $z-1$. The results of these two separate estimations are displayed in Tables 6 and 7. The classic and the international CAPMs Imply estimated constant relative risk aversions equal to 1.7032 and 1.1334 respectively. The P-values found are 0.1606 for the classic, unconditional CAPM and 0.049 for the international, unconditional CAPM:

Statement \#6: In their unconditional versions, the international CAPM is marginally rejected while the classic CAPM is not rejected.

By way of comparison, recall (Statement 1) that we have not rejected the international CAPM, conditioned on our cholce of instrumental variables, while we have rejected the classic CAPM conditioned on the same information set (Statement 2). Conditioning information plays a crucial role in discriminating between the two models.

Since the classic and the international CAPMs are nested, we can again use the dclassic CAPM as null hypothesis and the international CAPM as alternative, to test the significance of exchange rate pricing. We do this test in the context of the unconditional CAPMs in order to replicate earlier empirical attempts. We flt the classic, unconditional CAPM using the 
covariance matrix of moment conditions obtalned from the international, unconditional CAPM estimation. The result of this hypothesis test appears in Table 4. The P-value for the hypothesis of zero exchange risk pricing is: 0.74 .

Statement \#7: The hypothes Is that exchange rate risk is not priced [Ho: $\left.\lambda_{1}=0 ; 1=1 \ldots L\right]$ In the uncondicional version of the international, static CAPM Is not rejected.

This is the sense in which earlier empirlcal attempts based on the unconditional CAPMs were inconclusive.

In view of the result of Hansen and Richard (1987) - that unconditionally efficient portfolios are also conditionally efficient, -there is an apparent contradiction between our statement \#6 and our Statement \#2, as far as the classic CAPM is concerned. Indeed, statement \#6 says that the market portfollo may be considered unconditionally efficlent whereas Statement \#2 says that it is not conditionally efficient. Did we wrongly reject the classic CAPM in Statement \#2?

The classic CAPM is a first-order condition applied to the market portfollo. The appropriate form of a first-order condition depends on the space of strategles being considered. No statement of efficiency of a portfollo should be made without specifying the space of strategles within which that portfollo is efficient.

Hansen and Richard's result must be understood ceteris paribus. Their result means that a portfolio which is unconditionally efficient within a space of strategies is also conditionally efficient within that same space of strategies. The restriction that we have tested under the name "conditional (classic) CAPM" is a moment condition which is implied by the first-order 
condition of conditlonal efficiency, in the vast space of strategies that depend, In an unspecifled fashion, on the lagged information variables, 2 . The moment condition that we have tested under the name "unconditional (classic) CAPM $^{n}$ is the first-order condition of unconditional efficlency in the space of strategies with constant portfollo weights $(Z-1)$. Hansen and Richard's result does not apply to that comparison. ${ }^{29}$

In effect, the special case $z-1$, under which statements $\# 6$ and 7 were obtained, not only restricts the conditioning information of the econometrician; it also restricts the investors' information and, therefore, their space of strategies.

\section{Discussion of validity}

In this section, we evaluate the robustness of our results. ${ }^{30}$ we are particularly concerned that some of the assumptions of the GMM method may not be satisfied. Chief among those is the finite size of our sample while the $x^{2}$ tests are asymptotic (subsection 6.1). Other possible violations of GMM assumptions may arise from non stationarity of the variables (rates of return and instrumental variables) and from serial dependence in the sample moments. We look at these two aspects in subsections 6.2 and 6.4 . In addition, we want

29

${ }^{29}$ To illustrate the role played by the strategy space in deriving firstorder conditions, consider the problem of writing the unconditional efficiency of a portfollo policy among the strategles with portfolio weights which are linear in the information variables, $z$. In the notations of section 1 above, the first-order conditions of that problem would be:

$$
E\left[h_{j} z_{k}\right]-0 \text {, for all } j \text { and } k \text {. }
$$

These conditions are, in fact, identical to the particular implication of conditional efficiency that we have selected to express the conditional CAPM (Equation (1.14)). They do not resemble the condition that we have called the "unconditional CAPM".

${ }^{30}$ We already know that they are sensitive to the cholce of conditioning information. 
to check whether our results depend on the currency unit in which returns have been measured (subsection 6.3).

\subsection{Finite sample size}

Given the relative parsimony of our econometric specification (subsection 1.2), the finite-sample problem may not be as acute in the present application as it may be in others. With 8 assets, 6 instrumental variables, 30 parameters and 262 months of observations, the total number of numerical items to be estimated, equal to the number of parameters plus the elements of the weight matrix, is:

$$
30+54 \times 55 / 2-1515
$$

while the total number of datapoints concerning asset returns and instruments is equal to:

$$
262 \times(8+6)-3668 .
$$

The adjustment for finlte sample size suggested by Ferson and Foerster (1991) Implies that estimated variances of estimates should be multiplied by: $3668 /(3668-1515)-1.70$, or that the standard errors should be increased (and the $t$ statistics should be reduced) by $30 x$ only.

Monte Carlo experiments are the traditional answer to the question of finite sample size. ${ }^{31}$ They require that one simulate the stochastic processes for all the varlables of the model. Their stochastic processes must, therefore, either be known from theory -. which they are not in our case -. or be estimated prior to obtaining the sampling distributions on the coefficlents of the CAPM. Hence, Monte Carlo experiments themselves would be questionable. Instead of simulating the variables, data may be obtained from out-ofsample observations. Indeed, the ultimate test of the validity of a model is

\footnotetext{
${ }^{31}$ See Ferson and Foerster (1991).
} 
its ability to help in forecasting. In sample, raw statistical estimates from an OLS regression provide the best possible f1t; the overidentifying restrictions of a model only deteriorate the fit. Out of sample, however, a theoretical model can beat OLS. Unfortunately, splitting our sample of 262 observations into two subsamples proved perilous because each subsample was small. ${ }^{32} x^{2}$ statistics computed out of sample were excessively large. It does not seem possible at this point to validate the use of asymptotic statistics by such out-of-sample tests.

\subsection{Stationarity}

The only potential problem of non stationarity concerns the Eurodollar rate of interest. Other variables, such as the dividend yield and the bond yield, have been introduced as spreads relative to the Eurodollar rate. They are unlikely to be non stationary.

In order to allay possible concerns with this issue, we redid the critical estimation and test using as instrumental variable not the level of the Eurodollar rate but its first difference. The $x^{2}$ for the overidentifying restrictions of the International CAPM was equal to 22.7302 which produced a $p$-value equal to: 0.5358 . The $x^{2}$ for the overidentifying restrictions of the classic CAPM was equal to: 59.228 and produced a p-value equal to: 0.04 . The $x^{2}$ for the test of significance of the foreign-exchange risk premia, equal to 66.6093 lead to a $\mathrm{p}$-value of $1.7 \times 10^{-7}$. Hence, the results contained in Statements \#1, 2 and 3 are not overturned.

${ }^{32}$ For instance, subsamples of equal sizes contain $3668 / 2=1834$ datapoints. This number is to be compared to the number, 1515, of numerical elements to be estimated. 


\subsection{Measurement currency}

While the theoretical CAPMs themselves are invariant to the choice of the measurement currency, auxiliary Assumption 2 regrettably is not so Invariant. To ascertain the potential damage, we performed again the estimation of the two CAPMs and the tests of significance, using the Deutschemark, Instead of the U.S. dollar, as the unit in terms of which nominal rates of return were measured. The $x^{2}$ for the overidentifying restrictions of the international CAPM, equal to 28.686, produced a p-value equal to: 0.2322 . The $x^{2}$ for the overidentifying restrictions of the classic CAPM, equal to 71.115 , produced a $p$-value equal to: 0.0033 . The $x^{2}$ for the test of significance of the foreignexchange risk premia, equal to 68.314 , lead to a p-value of $10^{-7}$. The results contained in Statements $\| 1,2$ and 3 stand.

\subsection{Serlal dependence in the vector of sample moments} Autocorrelation in the vector of sample moments may affect the consistency of the varlance-covariance matrix of that vector. Newey and West (1987b) have proposed a weighting scheme for covarlance smoothing. However, the number of terms to be included in the scheme remains arbitrary. We have conducted experiments to determine the impact of covariance smoothing, depending on the number of months included in the scheme, on the test of overidentifying restrictions of the international CAPM:

$\begin{array}{lll}\text { Number of months } & x^{2} & \mathrm{p} \text {-value } \\ 0 & 28.8039 & 0.2276 \\ 1 & 24.2535 & 0.4472 \\ 2 & 21.3757 & 0.6165 \\ 3 & 20.4972 & 0.6682 \\ 4 & 19.0099 & 0.7515 .\end{array}$


The test result is not overturned.

\section{Testing for segmentation}

We have already accepted jointly all the overidentifying restrictions of the international conditional CAPM. It may be superfluous to test one of them in isolation. Nevertheless, we observe that the conditional, classic CAPM is rejected, in large part as a result of the introduction of currencies in the list of assets (see Section 4). One may therefore ralse the question of knowing whether currencies are priced differently from equity securities, 1.e. whether the foreign exchange market is segmented from the stock market.

In testing for segmentation, we cannot allow each asset to have a different matrix, as the model would then be underidentifled. Instead, we group assets into categories. There are many possible groupings. In line with the above observation, we recognize two groups or markets: equities and currencies. We estimate a conditional version of the international, static CAPM in which we relax the CAPM restriction that the $\phi s$ are the same for both asset categories. Then we test the hypothesis of equality of the $\phi$ s between the two categories. We only allow the prices of exchange rate risk to differ.

\section{TABLES 8 AND 9 GO HERE}

In Tables 8 and 9 , we display the $\chi^{2}$ value for the relaxed international CAPM and the $\phi$ parameters. The two tables correspond to two versions of the estimation. The definition (1.12) of the residual of the marginal rate of substitution forecast, $u_{t}$, involves the parameters $\phi$. The two versions of the estimation differ according to which set of parameters $\phi$ is used in the definition: those of the foreign-exchange market or those of the equity 
market. The results are not sensitive to the choice of specification.

In each block of parameter estimates of Tables 8 and 9, the first two parameters are the exchange-risk $\phi s$ measured in the equity market, the middle parameter is the element of the vector $\phi_{m}$ and the last two paramaters are the exchange-risk $\phi s$ of the foreign exchange market. There is some similarity between the exchange-risk $\phi s$ of the two markets. A forms comparative test is obtained by estimating the standard form of the international, conditional CAPM, with $\phi s$ restricted to being equal in the two financial markets, but using the weighting matrix of the relaxed model. The calculations for the corresponding Newey-West test are in Table 4. The P-value is 0.5845 or 0.7601 depending on the version of the test. Hence:

Statement \#8: In the International, conditlonal CAPM, the hypothesis of Integration of the international stock and forelgn exchange markets is not rejected.

\section{International vs dynamic CAPMs}

We pointed out in the introduction that a conditional, static CAPM is internally inconsistent. If it is conditional, it should be multiperiodic since investors anticipate the future variations of the instrumental variables and hedge them over their lifetime. Indeed, recent research in international financlal markets has made it a priority to use dynamic models. These come in two classes. The first class contains so-called "consumption CAPM" as in Breeden (1979), Lucas $(1978,1982)$; these are Euler condltions based on one investor's consumption stream; they are valid equally in the domestic or international context; their empirical test requires the measurement of 
consumption. ${ }^{33}$ The second class is based on the world market portfollo as in Merton (1973). ${ }^{34}$ since CAPMs of this second class are obtalned by aggregation, the composition of the world population of investors here agaln makes a difference.

The test of a full conditional, international, dynamic Merton-CAPM would require an extremely large number of assets as otherwise the model is not overidentified. We are not in a position to run a test with enough assets. But we can run a "horse race" between the two types of models in order to determine which should be our first priority: the Introduction of hedging risk premia as in the dynamic, classic CAPM or the introduction of exchange risk premia as in the static, International CAPM.

TABLE 10 GOES HERE

Table 10 contains the results of applying to international data a dynamic model in which all the independent, stochastic instrumental variables, ${ }^{35}$ with a one-perlod lead, are also priced risk factors. The P-value is found to be: 0.3450 .

Statement $\| 9:$ The dynamic, classic CAPM is not rejected by our International data.

${ }^{33}$ However, in the latent-varlable method [Hansen and Hodrick (1983), Gibbons and Ferson (1985), Hodrick and Srivastava (1984)), the assumption that each security's measure of risk is constant obviates the need to observe consumption. See, however, Wheatley's (1989) critique.

${ }^{34}$ See Ferson and Harvey $(1991 \mathrm{a}, \mathrm{b})$.

${ }^{35}$ I.e., all of them except the constant and the January dumny which are not stochastic, and the rate of return on the world market index which is colinear with the market factor. That leaves: the U.S. bond yield, the U.S. dividend yield and the Eurodollar interest rate. 
The "horse race" is not conclusive. The conditional, international CAPM and the dynamic CAPM are both accepted by the data.

Finally, we perform a test to verify the signiflcance of intertemporal hedging premia in the dynamic CAPM. This involves re-estimating the conditional, static CAPM, using the weighting matrix of the dynamic model. The resulting $x^{2}$ is equal to: 26.1627. Calculations for this test appear in Table 4. The P-value is: 0.0057 .

Statement \#10: The hypothesis of zero prices on Intertemporal hedging risks in the dynamic CAPM is rejected by our international data.

We have no evidence to conclude in favor of elther model.

\section{Conclusion}

Based on a sample of securities which included equities and currencles, our results show that forelgn-exchange risk premla are a signiflcant component of securities rates of return in the international financlal market, and that the international CAPM dominates the classic CAPM.

The parsimonious econometric speciflcation that we use here has undoubtedly helped in reaching this unequivocal conclusion. The parsimony was achieved in two ways. First, the estimation technique used made it possible to test the various CAPMs without specifying the behavior of the second moments of rates of return. Second, by relying on the concept of kernel estimation, we also obviated the need to estimate the behavior of the first moments of rates of return. Only the behavior of the investors' marginal rate of substituation had to be estimated.

The parsimony in the specification increases the power of the tests by 
reducing the number of parameters which have to be estimated. However, it makes it impossible to answer two interesting questions. Because the second moments are not specifled, it is not possible to determine how large the foreign exchange risk premia are relative to the classic reward for market covariance risk.

Because the first moments have not been specified, it is not possible to measure how much each asset deviates from a CAPM. Nevertheless, we were able to determine which assets cause the classic CAPM to be rejected in our sample We found that foreign exchange risk premia are needed chiefly in order to explain rates of return on currencles. Once these risk premla are included in the CAPM, no evidence of segmentation between currency markets and stock markets has been found. 
Adler, M. and B. Dumas, 1983, "International Portfollo Cholce and Corporation Finance: a Synthesis," Journal of Finance, 38, 925-984.

Bansal, R., D. Hsieh and R. VIswanathan, 1992, "A New Approach to International Arbitrage Pricing," working paper, Fuqua School of Business, Duke University.

Bekaert, G. and R. J. Hodrick, 1992, "Characterizing Predictable Components in Excess Returns on Equity and Forelgn Exchange Markets, "Journal of Finance, 47, 467-511.

Breeden, D., 1979, "An Intertemporal Asset Pricing Model with Stochastic Consumption and Investment Opportunities," Journal of Financial Economics, 7 , 265-296.

Breen, W., L. Glosten and R. Jagannathan, 1989, "Economic Significance of Predictable Variatlons in Stock Index Returns," Journal of FInance, 44, 1177 . 1190.

Chan, K. C., G. A. Karolyi and R. M. Stulz, 1991, "Global Financial Markets and the Risk Premium on U.S. Equity," Journal of Financial Economics, 32, 137 . 168.

Chen, N.-F., R. Roll and S. Ross, 1986, "Economic Forces and the Stock Market: Testing the APT and Alternative Asset Pricing Theorles," Journal of Business, $59,383-403$.

Cumby, R. E. and M. Obstfeld, 1984, "International Interest rate and Price Level Linkages under Flexible Exchange Rates: A Review of Recent Evidence, "In J. F. O. Bilson and R. C. Marston, eds, Exchange Rate Theory and Practice, (University of Chicago Press, Chicago), 121-151.

Eichenbaum, M. S., L. P. Hansen and K. J. Singleton, 1988, "A Time Series Analysis of Reepresentative Agent Models of Consumption and Leisure Cholce under Uncertainty," Quarterly Journal of Economics, 103, 51-78.

Elchenbaum, M. S. and L. P. Hansen, 1990, "Estimating Models with Intertemporal Substitution using Aggregate Time Serles, " Journal of Business and Economics Statistics, 8, 53-69.

Engel, C. and A. Rodrigues, 1989, "Tests of International CAPM with TimeVarying Covariances," Journal of Applied Econometrics, 4, 119-138.

Fama, E, and MacBeth..., 1973, "Risk, Return and Equilibrium: Emplrical Tests," Journal of Political Economy, 607-635.

Fama, E. and K. R. French, 1988, "Dividend Yields and Expected Stock Returns," Journal of Financial Economics, 22, 3-26.

Ferson, W. E. and S. R. Foerster, 1991, "Finite Sample Properties of the Generalized Method of Moments in Tests of Conditional Asset Pricing Models," working paper. University of Chicago. 
Ferson, W. E. and C. R. Harvey, 1991a, "The Variation of Economic Risk Premiuns," Journal of Polftical Economy.

Ferson, W. E. and C. R. Harvey, 1991b, "The Risk and Predictabllity of International Equity Returns," working paper, University of Chicago.

Foster, D. and T. Smith, 1992, "Assessing 2 Goodness of Fit of Asset Pricing Models: the Distribution of the Maximal $R^{2}$," working paper, Duke University, Fuqua School of Business.

Gallant, R. A., 1987, Nonlinear Statistlcal Models, New York, Wiley.

Gallant, R. A. and D. W. Jorgenson, 1979, "Statistical Inference for a System of Simultaneous, Nonlinear. Implicit Equations in the Context of Instrumental Varlables Estimation," Journal of Econometrlcs, 11, 275-302.

Gibbons, M. and W. Ferson, 1985, "Tests of Asset Pricing Models with Changing Expectations and an Unobservable Market Portfolio," Journal of Financlal

Economics, 14, 217-236.

Giovannini, A. and P. Jorion, 1987, "Interest Rates and Risk Premla in the Foreign Exchange and the Stock Narket," Journal of International Money and Finance, $107-123$.

Glovannini, A. and P. Jorion, 1988, "Forelgn Exchange RIsk Premla Once Again," Journal of International Money and Finance, 111-113.

Giovannini, A. and P. Jorion, 1989, "The Time-Variation of Risk and Return in the Foreign Exchange and Stock Markets," Journal of Finance, 307-325.

Hansen, L. P., 1982, "Large Sample Properties of Generalized Methods of Moments Estimators," Econometrica, 50, 1029-1054.

Hansen, L. P. and R, Jagannathan, 1991, "Implications of Security Market Data for Models of Dynamic Economies," Journal of Political Economy, 99, 225-261.

Hansen, L. P. and R. J. Hodrick, 1983, "Risk Averse Speculation in the Forward Exchange Market: an Econometric Analysis of Linear Models," in J. A. Frenkel, ed., Exchange Rates and International Macroeconomic, (UnIversity of Chicago Press, Chicago).

Hansen, L. P. and S. F. Rlchard, 1987, "The Role of Conditioning Information in Deducing Testable Restrictions Implied by Dynamic Asset Pricing Models," Econometrlca, 55, 587-613.

Harvey, C. R., 1989, "Time-Varying Conditional Covariances in Tests of Asset Pricing Models," Journal of Financial Economics, 24, 289-317.

Harvey, C. R., 1991, "The World Price of Covariance Risk, " Journal of Flnance. March.

Hodrick, R. J., 1987, "Risk, Uncertainty and Exchange Rates," NBER working paper no 2429.

Hodrick, R. J. and S. Srivastava, 1984, "An Investigation of Risk and Return 
In Forward Foreign Exchange," Journal of International Money and Finance, 3. 5-29.

Jorion, P., 1991, "The Pricing of Exchange Rate Risk in the Stock Market," Journal of Financial and Quantitative Analysis, forthcoming.

Kaminsky, G. and R. Peruga, 1990, "Can a Time-Varying Risk Premium Explain Excess Returns in the Forward Market for Foreign Exchange?, "Journal of International Economics, 28, 47-70.

Lucas, R. E., 1978, "Asset Prices in an Exchange Economy," Econometrica.

Lucas, R. E., 1982, "Interest Rates and Currency Prices, in a Two-country World, " Journal of Monetary Economics, 10, 335-360.

Merton, R, C., 1973, "An Intertemporal Asset Pricing Model," Econometrica, 41, $867-880$.

Newey, W. K. and K. D. West, 1987a, "Hypothesis Testing with Efficlent Method of Moments Estimation," International Economic Review, 28, 777-787.

Newey, W. K. and K. D. West, 1987b, "A Simple, Positive Semi-Definite, Hetroskedasticlty and Autocorrelation Consistent Covariance Matrix,"

Econometrica, 55, 703-708.

Sercu, P., 1980, "A Generalization of the International Asset Pricing Mode1," Flnance, $91-135$.

Solnik, B., 1974, "An Equilibrium Model of the International Capital Market," Journat of Economic Theory, 8, 500-524.

Solnik, B., 1974, "The International Pricing of Risk: An Empirical Investigation of the World Capital Market Structure, " Journal of Finance, 29, $48 \cdot 54$.

Solnik, B., 1993, "The Performance of International Strategies using Conditioning Information," Journal of Empirical Finance, 1, 33-56.

Stehle, R., 1977, "An Empirical Test of the Alternative Hypotheses of National and International Pricing of Risky Assets," Journal of Flnance, 32, 493-502.

Wheatley, S. M., 1989, "A Critique of Latent Vartable Tests of Asset Pricing Models," Journal of Financial Economics, 23, 325-338. 
</ref_section> 
Table 1 Summary statistics

number of obs- 262.00000 [March 1970 - December 1991]

Excess returns

$\begin{array}{lll} & \text { MEAN/month } & \text { STD DEV/month } \\ & & \\ \text { German equity } & 0.0050726679 & 0.062362157 \\ \text { U.K. equity } & 0.0065975649 & 0.077541166 \\ \text { Japanese equity } & 0.0090457824 & 0.065944529 \\ \text { U.S. equity } & 0.0024764962 & 0.046825699 \\ \text { Deutschemark } & 0.0017136374 & 0.034912228 \\ \text { British Pound } & 0.0017428969 & 0.031856602 \\ \text { Japanese Yen } & 0.0027198626 & 0.033234643 \\ \text { World equity } & 0.0031789237 & 0.043619171\end{array}$

Instruments

MEAN STDEV PAIRWISE CORRELATIONS

$\begin{array}{lrrrrrrr}\text { Cst } & 1.00000 & 0.00000 & & & & & \\ r_{(-1)} & 0.0361454 & 0.521389 & 1.0 & 0.093 & 0.27 & 0.26 & -0.25 \\ J_{\text {and }} & 0.0801527 & 0.272049 & 0.093 & 1.0 & -0.013 & 0.0025 & 0.00038 \\ \text { USbony-E\$ } & 0.154504 & 2.13435 & 0.27 & -0.013 & 1.0 & 0.78 & -0.74 \\ \text { USDivy-ES } & -4.70187 & 2.68230 & 0.26 & 0.0025 & 0.78 & 1.0 & -0.97 \\ \text { Euro\$ } & 8.90630 & 3.27651 & -0.25 & 0.00038 & -0.74 & -0.97 & 1.0\end{array}$

German equity

$\begin{array}{lcccr}\text { Coeff } & \text { Value } & \text { NW Std Err } & \text { T-stat } & \text { OLS Std Err } \\ \text { Cst } & -0.000500044 & 0.0172819 & -0.0289346 & 0.0186013 \\ r_{\mathrm{m}}(-1) & 0.00320124 & 0.00923349 & 0.346699 & 0.00760901 \\ \text { Jand } & -0.00930024 & 0.0127758 & -0.727958 & 0.0140009 \\ \text { USbon-ES } & 0.00251177 & 0.00272403 & 0.922079 & 0.00286999 \\ \text { USDiv-ES } & 0.00758596 & 0.00537947 & 1.41017 & 0.00589303 \\ \text { Euro\$ } & 0.0046577 & 0.0041725 & 1.11629 & 0.0044989\end{array}$

Rsquared is $\quad 0.0366406$

residual auto correlations

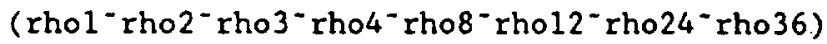
.0 .018
$-0.028$
0.071
0.052
$-0.015$
$-0.067$
0.031
0.054 
Table 1 continued (1)

U.K. equity

$\begin{array}{lcrrr}\text { Coeff } & \text { Value } & \text { NW Std Err } & \text { T-stat } & \text { OLS Std Err } \\ \text { Cst } & -0.0241160 & 0.0192274 & -1.25425 & 0.0225987 \\ \text { r }(-1) & 0.00149542 & 0.0102895 & 0.145335 & 0.00924421 \\ \text { Jand } & 0.0457431 & 0.0272173 & 1.68066 & 0.0170097 \\ \text { USbon-E\$ } & .000393302 & 0.00370134 & 0.106259 & 0.00348676 \\ \text { USDiv-E\$ } & 0.0215969 & 0.00744184 & 2.90210 & 0.00715947 \\ \text { Euro\$ } & 0.014426 & 0.0051522 & 2.79987 & 0.0054658 \\ & & & & \end{array}$

\section{residual auto correlations}

(rho1"rho2"rho3"rho4"rho8"rho12"rho24'rho36)
0.033
$-0.12$
0.035
0.023
$-0.022$
$-0.054$
$0.035 \quad-0.065$

Japanese equity

$\begin{array}{lcrrr}\text { Coeff } & \text { Value } & \text { NW Std Err } & \text { T-stat } & \text { OLS Std Err } \\ \text { Cst } & 0.0235762 & 0.0192123 & 1.22715 & 0.0195348 \\ \text { r }(-1) & 0.0105354 & 0.0102990 & 1.02295 & 0.00799090 \\ \text { Jand } & 0.00524982 & 0.0109185 & 0.480818 & 0.0147036 \\ \text { USbon-ES } & 0.00187947 & 0.00277557 & 0.677149 & 0.00301403 \\ \text { USDiv-ES } & 0.00312446 & 0.00564541 & 0.553451 & 0.00618880 \\ \text { Euro\$ } & -0.00010460 & 0.0044475 & -0.0235194 & 0.0047247\end{array}$

Rsquared is

0.0498163

residual auto correlations

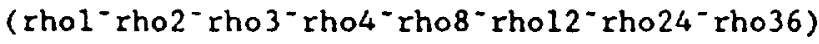

$\begin{array}{llllllll}-0.029 & -0.027 & 0.041 & 0.040 & 0.070 & 0.063 & .0 .018 & 0.079\end{array}$

U.S. equity

\begin{tabular}{lrrrr} 
Coeff & \multicolumn{1}{c}{ Value } & NW Std Err & \multicolumn{1}{c}{ T-stat } & OLS Std Err \\
Cst & -0.0222053 & 0.0134187 & -1.65480 & 0.0136891 \\
$\boldsymbol{r}_{\mathrm{m}}(-1)$ & $-3.74043 \mathrm{E}-05$ & 0.00641996 & -0.00582625 & 0.00559963 \\
Jand & 0.0191409 & 0.0125185 & 1.52901 & 0.0103036 \\
USbon-ES & 0.00144035 & 0.00231997 & 0.620850 & 0.00211209 \\
USDiv-ES & 0.0135140 & 0.00499992 & 2.70284 & 0.00433681 \\
EuroS & 0.0097086 & 0.0036650 & 2.64896 & 0.0033109
\end{tabular}

Rsquared is $\quad 0.0746112$

residual auto correlations

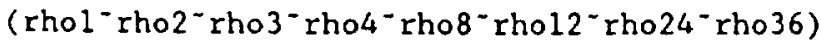
0.015
.0 .052
0.013
0.0084
0.019
$0.039 \quad-0.030 \quad-0.096$ 
Table 1 continued (2)

Deutschemark

$\begin{array}{lccrr}\text { Coeff } & \text { Value } & \text { NW Std Err } & \text { T-stat } & \text { OLS Std Err } \\ \text { Cst } & 0.0276441 & 0.00996991 & 2.77275 & 0.0101463 \\ r_{\text {m }}(-1) & -0.0111683 & 0.00405834 & -2.75194 & 0.00415043 \\ \text { Jand } & -0.0149178 & 0.00746202 & -1.99916 & 0.00763696 \\ \text { USbon-ES } & 0.00115600 & 0.00153799 & -0.751631 & 0.00156547 \\ \text { USDiv-E\$ } & 0.00150231 & 0.00314975 & 0.476963 & 0.00321443 \\ \text { Euro\$ } & -0.0019187 & 0.0024410 & -0.786037 & 0.0024540\end{array}$

Rsquared is $\quad 0.0854548$

residual auto correlations

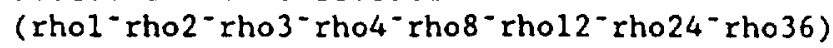
0.048
0.069
$-0.022-0.0095$
$-0.016$
$-0.014 \quad-0.012$
0.062

British Pound

\begin{tabular}{lccrr} 
Coeff & Value & NW Std Err & \multicolumn{1}{c}{ T-stat } & OLS Std Err \\
Cst & 0.0166959 & 0.00788918 & 2.11631 & 0.00950770 \\
$r_{\mathrm{m}}(-1)$ & -0.00587173 & 0.00392309 & -1.49671 & 0.00388921 \\
Jand $_{\text {USbon-ES }}$ & -0.00176166 & 0.00626974 & -0.280978 & 0.00715631 \\
USb & -0.00153343 & 0.00147796 & -1.03753 & 0.00146695 \\
USDiv-E\$ & 0.00280898 & 0.00286324 & 0.981050 & 0.00301212 \\
Euro\$ & -0.00012971 & 0.0020446 & -0.0634376 & 0.0022996
\end{tabular}

Rsquared is $\quad 0.0355085$

residual auto correlations

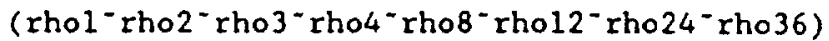
0.090
0.067
$-0.019$
0.029
$-0.048-0.010$
0.014
0.019

Japanese Yen

\begin{tabular}{lcrrr} 
Coeff & Value & NW Std Err & \multicolumn{1}{c}{ T-stat } & \multicolumn{1}{c}{ OLS Std Err } \\
Cst & 0.0178674 & 0.00924367 & 1.93293 & 0.00978246 \\
r $(-1)$ & -0.00268856 & 0.00418139 & -0.642982 & 0.00400160 \\
Jand & -0.0112784 & 0.00621528 & -1.81462 & 0.00736312 \\
USbon-E\$ & 0.000873910 & 0.00148191 & 0.589718 & 0.00150934 \\
USDiv-ES & 0.00120969 & 0.00349170 & 0.346448 & 0.00309917 \\
Euro\$ & -0.00096488 & 0.0026206 & -0.368185 & 0.0023660
\end{tabular}

Rsquared is $\quad 0.0618756$

residual auto correlations

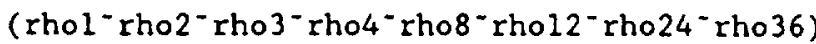
0.043
0.0016
0.036
$0.050 \quad-0.0059$
$\begin{array}{lll}0.051 \quad-0.086 & -0.025\end{array}$ 
Table 1 continued (3)

World equity

$\begin{array}{lcrrr}\text { Coeff } & \text { Value } & \text { NW Std Err } & \text { T-stat } & \text { OLS Std Err } \\ \text { Cst } & -0.0127904 & 0.0127695 & -1.00163 & 0.0126632 \\ r_{\text {m }}(-1) & 0.00300301 & 0.00576226 & 0.521152 & 0.00517998 \\ \text { Jand } & 0.0173971 & 0.0104891 & 1.65858 & 0.00953138 \\ \text { USbon-ES } & 0.00145192 & 0.00204164 & 0.711153 & 0.00195380 \\ \text { USDiv-ES } & 0.0116415 & 0.00406912 & 2.86093 & 0.00401179 \\ \text { Euro\$ } & 0.0077449 & 0.0030994 & 2.49888 & 0.0030627\end{array}$

Rsquared is $\quad 0.0874106$

residual auto correlations

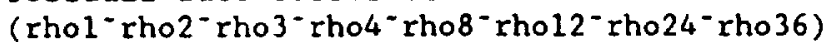

$\begin{array}{llllllll}0.0048 & -0.074 & 0.030 & -0.0047 & 0.0064 & 0.038 & -0.0061 & -0.056\end{array}$ 
Table 2 Estimation of the conditional, international CAPM number of observation- 262.00000: number of factors- 4.0000000

$\begin{array}{lrrr}\text { Coeff } & \text { Value } & \text { Std Err } & \text { T-stat } \\ \text { deltas } & 0.1003 & 0.2603 & 0.3854 \\ \text { Cst } & -0.0991 & 1.3946 & -0.0711 \\ \left.r_{\text {m }}-1\right) & 1.3406 & 0.5416 & 2.4752 \\ \text { JanD } & -0.0358 & 0.0384 & -0.9319 \\ \text { USbon-ES } & -0.0197 & 0.0863 & -0.2281 \\ \text { USDiv-ES } & 0.0195 & 0.0645 & 0.3016 \\ \text { Euro\$ } & & & \end{array}$

phis

Constants

$\begin{array}{lrrr}\text { \$/DM } & 22.4735 & 14.7214 & 1.5266 \\ \text { \$/Pound } & 19.3737 & 23.3126 & 0.8310 \\ \text { \$/Yen } & 18.2531 & 18.0832 & 1.0094 \\ \text { Wldmkt } & -18.5363 & 7.6691 & -2.4170\end{array}$

$\begin{array}{lrrr}r_{\mathrm{m}}^{(-1)} & & & \\ \text { \$/DM } & -371.3151 & 113.5849 & -3.2691 \\ \text { \$/Pound } & 180.1012 & 90.2006 & 1.9967 \\ \text { \$/Yen } & 100.6250 & 77.2074 & 1.3033 \\ \text { Wldmkt } & 31.6038 & 31.4958 & 1.0034 \\ & & & \\ \text { January dummy } & & & \\ \text { \$/DM } & -60.4603 & 18.9181 & -3.1959 \\ \text { \$/Pound } & 40.6945 & 22.2498 & 1.8290 \\ \text { \$/Fen } & 0.8343 & 25.5178 & 0.0327 \\ \text { Wldmkt } & 22.8588 & 8.6047 & 2.6566\end{array}$

U.S. bond yield - Eurodollar rate

$\begin{array}{lrrr}\text { \$/DM } & -1.7018 & 3.8414 & -0.4430 \\ \text { \$/Pound } & -7.9977 & 4.0051 & -1.9969 \\ \text { \$/Yen } & 3.4880 & 2.7192 & 1.2827 \\ \text { Wldmkt } & 1.9627 & 1.1707 & 1.6765\end{array}$

U.S. dividend yield - Eurodollar rate

$\begin{array}{lrrr}\text { \$/DM } & 0.4544 & 4.9157 & 0.0924 \\ \text { \$/Pound } & 5.6074 & 4.7711 & 1.1753 \\ \text { \$/Yen } & -3.7700 & 3.6377 & -1.0364 \\ \text { Wldmkt } & 10.1277 & 2.2334 & 4.5346\end{array}$

Eurodollar

$\begin{array}{lrrr}\text { S/DM } & -1.6611 & 3.3473 & -0.4962 \\ \text { \$/Pound } & 0.5133 & 4.1589 & 0.1234 \\ \text { \$/Yen } & -3.6828 & 3.0457 & -1.2092 \\ \text { Wldmkt } & 7.6852 & 1.7015 & 4.5168\end{array}$

no. of iterations: 2; weighing matrix updated: 15 times

Chi-square : 28.803934; RIGHT TAIL P-value : 0.227597

Degrees of freedom : 24.000000 
Table 3

Estimation of the conditional, classic CAPM

nbre observation- 262.00000

nbre facteurs= 1.0000000

Coeff Value Std Err T-stat

deltas (vector $\delta$ )

\begin{tabular}{|c|c|c|c|}
\hline $\begin{array}{l}\text { Cst } \\
\tau_{\text {mand }}(-1) \\
\text { JaSbon-ES } \\
\text { USb } \\
\text { USD -ES } \\
\text { Euro\$ }\end{array}$ & $\begin{array}{r}-0.0637 \\
0.5866 \\
0.1264 \\
-0.0425 \\
0.1090 \\
0.0792\end{array}$ & $\begin{array}{l}0.1042 \\
0.5408 \\
0.1221 \\
0.0180 \\
0.0536 \\
0.0385\end{array}$ & $\begin{array}{r}-0.6108 \\
1.0847 \\
1.0347 \\
-2.3625 \\
2.0345 \\
2.0603\end{array}$ \\
\hline
\end{tabular}

phis (vector $\phi_{\text {m }}$ )

$\begin{array}{lrrr}\text { Cst } & -9.6176 & 5.8744 & -1.6372 \\ r_{\text {m }}(-1) & 24.6887 & 24.9418 & 0.9899 \\ \text { Jand } & 0.0802 & 2.8527 & 0.0281 \\ \text { USbon-ES } & 0.0442 & 0.8240 & 0.0536 \\ \text { USDiv-ES } & 11.1430 & 1.8205 & 6.1207 \\ \text { Euro\$ } & 7.5439 & 1.3841 & 5.4504\end{array}$

no. of iterations: $\quad 4.000000$

weighing matrix updated $\quad 7.000000$ times

Chi-square : 69.118881

RIGHT TAIL P-value : 0.005252

Degrees of freedom : $\quad 42.000000$ 
Table 4 Hypotheses tests

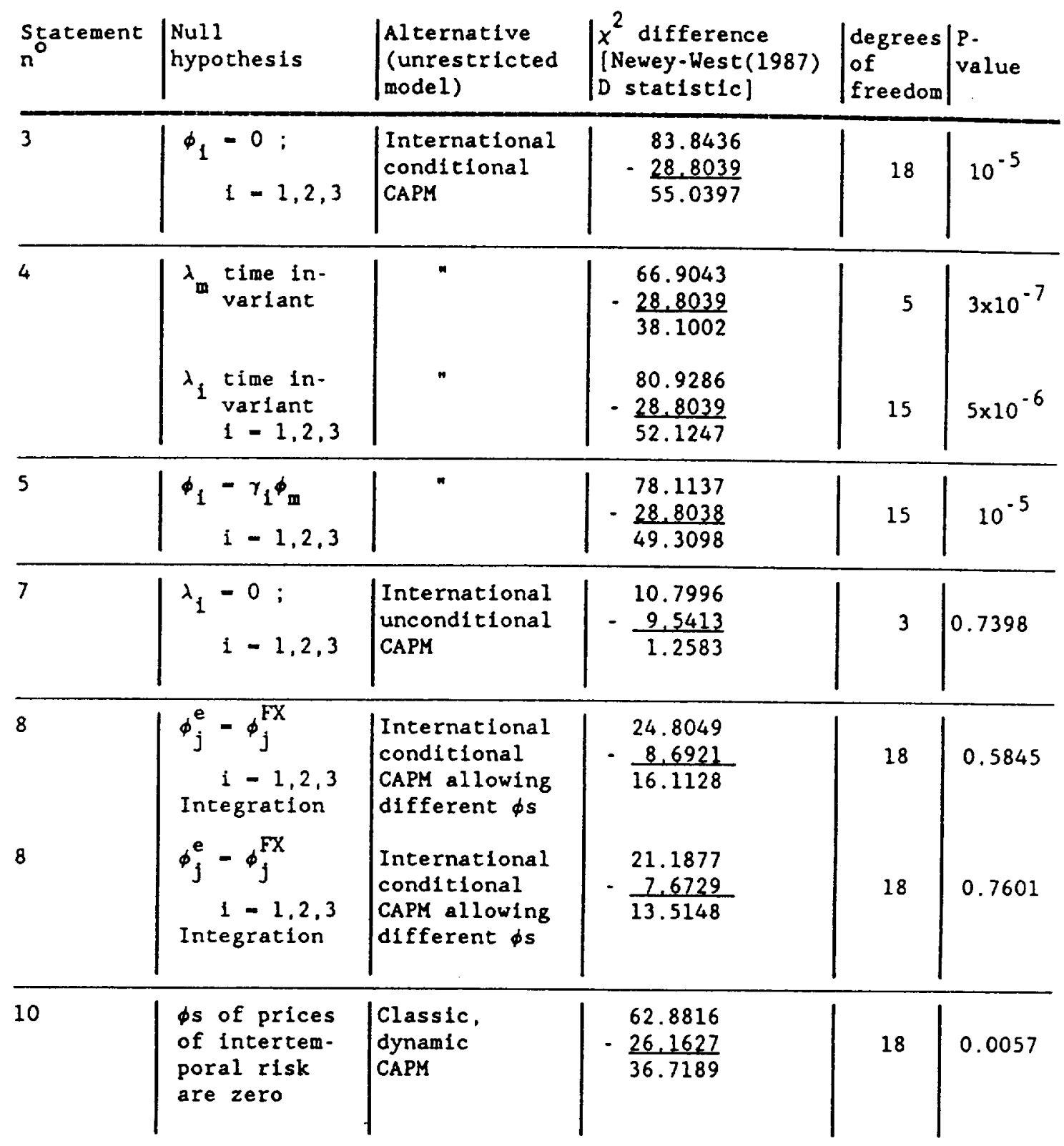


Table 5

Analysis of chi squares

Table 5 shows the decompositions of various $x^{2}$ based on neglecting the elements outside the diagonal blocks. The last two lines of each column serve as a check that the $\chi^{2}$ so reconstructed is very close to the statistic measured originally. The first column of Table 5 contains the decomposition of the $x^{2}$ statistic which served to test the overidentifying restrictions of the classic CAPM (supportigg Statement \#2); the second column contains the decomposition of the $x^{2}$ f the international CAPM (Statement $\# 1$ ) and the third column pertains to the $x^{2}$ difference of the test of significance of exchange risk premia (Statement $\$ 3$ ).

$$
\begin{aligned}
& x^{2} \text { of classic } \\
& \text { CAPM }
\end{aligned}
$$

Marginal Rate

0.94731513

German equ.

U.K. equity

2. 2855163

3. 8707528

Japanese equ

US equity

5.4527897

1.6330651

Deutschemark

25.754764

British Pound

Japanese Yen

World mkt

.5737112

13.842784

1.7038594

Sun (reconstructed $\chi^{2}$ ):

$$
62.064558
$$

Actual $x^{2}$ (from tables 2,3 and 4 )

$$
69.1188
$$

28.8039 $x^{2}$ of signifi-

cance test

2.9077518

5.8583204

4. 3948730

2.7480713

0.68853614

20.520073

7.8175743

9.5830724

0.99721894

55.515491

55.039700 
Table 6

Estimation of the unconditional, classic CAPM

number of observation- 262.00000

number of factors- 1.0000000

$\begin{array}{llll}\text { Coeff } & \text { Value } & \text { Std Err } & \text { T-stat } \\ \delta=\lambda_{0} & 0.0055 & 0.0092 & 0.5921 \\ \phi_{\mathrm{m}}-\lambda_{\mathrm{m}} & 1.7032 & 1.4661 & 1.1617\end{array}$

no. of iterations: $\quad 2.000000$

weighing matrix updated 4.000000 times

Chi-square : $\quad 10.527019$

RIGHT TAIL P-value : $\quad 0.160622$

Degrees of freedom : $\quad 7.000000$ 
Table 7

Estimation of the unconditional, international CAPM

number of observation- 262.00000

number of factors- 4.0000000

$\begin{array}{lrrr}\text { Coeff } & \text { Value } & \text { Std Err } & \text { T-stat } \\ \delta=\lambda_{0} & 0.0099 & 0.0121 & 0.8156 \\ \text { कs }=\lambda s & & & \\ \text { S/DM } & -0.3607 & 2.6090 & -0.1383 \\ \text { S/Pound } & 0.3417 & 2.6257 & 0.1301 \\ \text { \$/Yen } & 2.2238 & 2.4499 & 0.9077 \\ \text { Wldmkt } & 1.1334 & 1.5366 & 0.7376\end{array}$

no. of lterations: 2.000000

welghing matrix updated 4.000000 times

Chi-square : 9.541291

RIGHT TAIL P-value : $\quad 0.048906$

Degrees of freedom: $\quad 4.000000$ 
Table 8: Estimation of the International, segmented CAPM (version 1) number of observation- 262; number of factors- 4.

\begin{tabular}{lrrr}
$\begin{array}{l}\text { Coeff } \\
\text { deltas }\end{array}$ & \multicolumn{1}{l}{ Value } & Std Err & \multicolumn{1}{c}{ T-stat } \\
\hline Cst & 0.5091 & 0.3803 & 1.3388 \\
Im $(-1)$ & -1.6740 & 2.1991 & -0.7612 \\
JanD & 2.0263 & 1.2965 & 1.5629 \\
USbon-E\$ & -0.1315 & 0.0644 & -2.0431 \\
USDiv-E\$ & -0.0046 & 0.1444 & -0.0315 \\
Euro\$ & -0.0278 & 0.1022 & -0.2722
\end{tabular}

phis

Constants

$\begin{array}{lrrr}\text { S/DM } & 36.1297 & 42.0897 & 0.8584 \\ \text { \$/Pound } & -52.4139 & 48.0699 & -1.0904 \\ \text { \$/Yen } & 47.8305 & 43.6819 & 1.0950 \\ \text { Wldmkt } & -21.2685 & 12.4932 & -1.7024 \\ \text { \$/DM } & 33.6442 & 14.5566 & 2.3113 \\ \text { \$/Pound } & -6.1650 & 23.1124 & -0.2667 \\ \text { \$/Yen } & 20.0105 & 19.2246 & 1.0409\end{array}$

$r_{\mathrm{m} / \mathrm{DM}}(-1)$

$-55.9196$

279.6538

$-0.2000$

$\$$ /Pound $\quad-166.8245$

217.1752

$-0.7682$

S/Yen 270.0335

Wldrkt

$-3.5697$

\$ DH

$-292.9597$

151.9910

1.7766

$52.1261 \quad-0.0685$

$\$ /$ Pound

93.0163

120.4788

$-2.4316$

S/Yen

138.2928

88.9139

1.0461

1.6142

January dummy

$\begin{array}{lrrr}\text { \$/DM } & -42.2269 & 65.0947 & -0.6487 \\ \text { \$/Pound } & 130.0524 & 62.2055 & 2.0907 \\ \text { \$/Yen } & -96.1994 & 72.5506 & -1.3260 \\ \text { Wldmkt } & 41.7203 & 20.9126 & 1.9950 \\ \text { \$/DM } & -80.0846 & 36.9177 & -2.1693 \\ \text { \$/Pound } & 48.1513 & 38.5100 & 1.2504 \\ \text { \$/Yen } & 10.4337 & 30.2642 & 0.3448\end{array}$

U.S, bond yield - Eurodollar rate

$\begin{array}{lrrr}\text { \$/DM } & -1.9061 & 9.5978 & -0.1986 \\ \text { \$/Pound } & 1.5393 & 9.4907 & 0.1622 \\ \text { \$/Yen } & -1.5786 & 6.1936 & -0.2549 \\ \text { Wldmkt } & 3.3095 & 2.1104 & 1.5682 \\ \text { \$/DM } & -3.9312 & 3.7230 & -1.0559 \\ \text { \$/Pound } & -2.8167 & 3.3779 & -0.8339 \\ \text { \$/Yen } & 3.1289 & 3.0251 & 1.0343\end{array}$




\begin{tabular}{lrrr} 
U.S. dividend & \multicolumn{3}{c}{ yield . Eurodollar rate } \\
S/DM & -8.6394 & 11.0765 & -0.7800 \\
\$/Pound & 14.9430 & 12.0680 & 1.2382 \\
\$/Yen & -6.4283 & 7.4563 & -0.8621 \\
Wldmkt & 9.2373 & 3.5354 & 2.6128 \\
\$/DM & -1.2091 & 5.2098 & -0.2321 \\
\$/Pound & 5.8209 & 5.7021 & 1.0208 \\
\$/Yen & -4.3609 & 4.0271 & -1.0829 \\
& & & \\
Eurodollar & & & \\
\$/DM & -8.3218 & 7.9750 & -1.0435 \\
\$/Pound & 13.4831 & 9.0065 & 1.4970 \\
\$/Yen & -7.9602 & 6.8058 & -1.1696 \\
Wldmkt & 7.3253 & 2.2320 & 3.2820 \\
\$/DM & -3.9594 & 3.5773 & -1.1068 \\
\$/Pound & 3.7924 & 4.7503 & 0.7983 \\
\$/Yen & -4.1970 & 3.2781 & -1.2803
\end{tabular}

no. of iterations: 2 ; weighing matrix updated: 19 times Chi-square : $\quad 8.692101$; RIGHT TAIL P-value : 0.191649 Degrees of freedom: 6.000000 
Table 9: Estimation of the segmented, international CAPM (version 2) number of observation- 262.00000; number of factors- 4.0000000

\begin{tabular}{lrrr}
$\begin{array}{l}\text { Coeff } \\
\text { deltas }\end{array}$ & Value & Std Err & T-stat \\
\hline Cst & 0.2140 & 0.2634 & 0.8124 \\
rd $(-1)$ & -0.6637 & 1.4620 & -0.4539 \\
Jand & 1.3386 & 0.7237 & 1.8498 \\
USbon-E\$ & -0.0449 & 0.0413 & -1.0869 \\
USDiv-E\$ & -0.0378 & 0.0870 & -0.4346 \\
Euro\$ & -0.0086 & 0.0663 & -0.1293
\end{tabular}

phis

Constants

$\begin{array}{lrrr}\text { \$/DM } & 29.2287 & 42.9409 & 0.6807 \\ \text { \$/Pound } & -51.9689 & 48.8381 & -1.0641 \\ \text { \$/Yen } & 60.9716 & 44.2389 & 1.3782 \\ \text { Wldmkt } & -20.8490 & 12.1863 & -1.7109 \\ \text { \$/DM } & 33.0655 & 14.4696 & 2.2852 \\ \text { \$/Pound } & -5.4704 & 22.5615 & -0.2425 \\ \text { \$/Yen } & 21.3601 & 19.0982 & 1.1184\end{array}$

$\begin{array}{lrrr}r_{m}(-1) & & & \\ \text { \$/DM } & -202.3558 & 288.8460 & -0.7006 \\ \text { \$/Pound } & -53.2066 & 236.8282 & -0.2247 \\ \text { \$/Yen } & 276.6722 & 151.3733 & 1.8277 \\ \text { Wldmkt } & -10.4136 & 51.7077 & -0.2014 \\ \text { \$/DM } & -320.2574 & 120.1331 & -2.6659 \\ \text { \$/Pound } & 104.1593 & 91.9665 & 1.1326 \\ \text { \$/Yen } & 161.4160 & 85.0993 & 1.8968 \\ & & & \\ \text { January dummy } & & & \\ \text { \$/DM } & -17.1532 & 58.2276 & -0.2946 \\ \text { \$/Pound } & 108.4984 & 48.1470 & 2.2535 \\ \text { \$/Yen } & -111.7707 & 76.8188 & -1.4550 \\ \text { W1dmkt } & 31.4578 & 13.9482 & 2.2553 \\ \text { \$/DM } & -61.2028 & 25.2392 & -2.4249 \\ \text { \$/Pound } & 35.3119 & 27.4238 & 1.2876 \\ \text { \$/Yen } & 5.0272 & 26.5950 & 0.1890\end{array}$

U.S. bond yield - Eurodollar rate

$\begin{array}{lrrr}\text { S/DM } & 3.1298 & 11.0338 & 0.2837 \\ \text { S/Pound } & -1.5927 & 10.4763 & -0.1520 \\ \text { \$/Yen } & -3.4142 & 6.2584 & -0.5455 \\ \text { W1dmkt } & 3.4879 & 1.8967 & 1.8389 \\ \text { \$/DM } & -3.6437 & 3.8856 & -0.9377 \\ \text { \$/Pound } & -2.5355 & 3.3989 & -0.7460 \\ \text { S/Yen } & 2.7431 & 3.0982 & 0.8854\end{array}$


U.S. dividend yield - Eurodollar rate

$\begin{array}{lrrr}\text { \$/DM } & -9.6946 & 10.8343 & -0.8948 \\ \text { \$/Pound } & 17.2742 & 11.6383 & 1.4842 \\ \text { \$/Yen } & -5.8251 & 7.2185 & -0.8070 \\ \text { Wldmkt } & 7.7501 & 3.9244 & 1.9749 \\ \text { \$/DM } & -0.9425 & 4.8740 & -0.1934 \\ \text { \$/Pound } & 5.4475 & 5.0615 & 1.0763 \\ \text { \$/Yen } & -3.6385 & 3.9955 & -0.9106 \\ & & & \\ \text { urodollar } & & & \\ \text { \$/DM } & -7.7742 & 7.6121 & -1.0213 \\ \text { \$/Pound } & 14.4699 & 8.3437 & 1.7342 \\ \text { \$/Yen } & -8.9216 & 6.7563 & -1.3205 \\ \text { W1dmkt } & 6.5321 & 2.3685 & 2.7579 \\ \text { \$/DM } & -3.8402 & 3.3305 & -1.1530 \\ \text { \$/Pound } & 3.4585 & 4.3464 & 0.7957 \\ \text { \$/Yen } & -3.8658 & 3.1596 & -1.2235\end{array}$

no. of Iterations: 2; welghing matrix updated: 21 times

Chi-square: 7.672877 ; RIGHT TAIL P-vaiue : 0.263062

Degrees of freedom: 6.000000 
Table 10

Estimation of the dynamic, classic CAPM

number of observations- 262; number of factors- 4

\begin{tabular}{lrrr}
$\begin{array}{l}\text { Coeff } \\
\text { deltas }\end{array}$ & \multicolumn{1}{l}{ Value } & Std Err & T-stat \\
\hline Cst & 0.5707 & 0.6156 & 0.9271 \\
Im $(-1)$ & -1.1738 & 3.5331 & -0.3322 \\
JanD & -0.0929 & 0.5821 & -0.1597 \\
USbon-ES & 0.1251 & 0.0842 & 1.4861 \\
USDiv-ES & -0.2665 & 0.1970 & -1.3531 \\
Euro\$ & -0.2026 & 0.1655 & -1.2242
\end{tabular}

phis

Constants

$\begin{array}{lrrr}\text { Wldmkt } & -1.6416 & 5.0725 & -0.3236 \\ \text { instr.\#1 } & -23.3693 & 7.5118 & -3.1110 \\ \text { instr \#2 } & -207.8525 & 70.3929 & -2.9527 \\ \text { instr \#3 } & -74.2577 & 28.5741 & -2.5988 \\ & & & \\ \text { (-1) } & & & \\ \text { Wldmkt } & -2.2503 & 12.5635 & -0.1791 \\ \text { instr.\#1 } & 3.4945 & 18.0170 & 0.1940 \\ \text { instr \#2 } & 9.9653 & 226.9270 & 0.0439 \\ \text { instr \#3 } & 114.3082 & 84.5685 & 1.3517\end{array}$

$\begin{array}{crrr}\text { January dummy } & & & \\ \text { Wldmkt } & 2.4259 & 1.9730 & 1.2296 \\ \text { instr.\#1 } & -1.2790 & 6.7022 & -0.1908 \\ \text { instr } \# 2 & -20.0728 & 65.0969 & -0.3084 \\ \text { instr } \$ 3 & -18.4000 & 29.9821 & -0.6137\end{array}$

$\begin{array}{lcrr}\text { U.S. bond yield- Eurodollar rate } & \\ \text { Wldmkt } & 1.2404 & 0.6894 & 1.7993 \\ \text { instr.\#1 } & 2.2638 & 0.8486 & 2.6676 \\ \text { instr \#2 } & 32.7672 & 11.4101 & 2.8718 \\ \text { instr \#3 } & 11.9770 & 4.9997 & 2.3955\end{array}$

U.S. dividend yield - Eurodollar rate

$\begin{array}{lrrr}\text { Widmkt } & -3.4455 & 1.8682 & -1.8443 \\ \text { instr.\#1 } & 1.7900 & 1.6597 & 1.0786 \\ \text { instr \#2 } & -21.9552 & 23.3186 & -0.9415 \\ \text { Instr \#3 } & 2.0741 & 9.6356 & 0.2153\end{array}$

$\begin{array}{crrr}\text { Eurodollar } & & & \\ \text { Wldmkt } & -1.9863 & 1.3934 & -1.4255 \\ \text { instr.\#1 } & 3.4080 & 1.4876 & 2.2909 \\ \text { Instr \#2 } & 8.0341 & 16.0956 & 0.4991 \\ \text { instr \#3 } & 9.3667 & 7.1165 & 1.3162\end{array}$

no. of iterations: 2; weighing matrix updated: 12 times Chf-square : 26.162706; RIGHT TAIL P-value : 0.344961 Degrees of freedom : 24.000000 